\title{
Iron-catalyzed one-pot reactions of $o$-aryloxybenzaldehydes to xanthones
}

\author{
YANG JingYu, DONG ChunYi, LI HaiYan, LI HongFeng \& LI YanZhong* \\ Shanghai Key Laboratory of Green Chemistry and Chemical Processes, Department of Chemistry, East China Normal University, Shanghai \\ 200062, China
}

Received January 1, 2012; accepted January 31, 2012; published online April 28, 2012

\begin{abstract}
An efficient one-pot procedure for the synthesis of multisubstituted xanthone derivatives using Fe-catalyzed reactions of 2-aryloxybenzaldehydes followed by DDQ (2,3-dichloro-5,6-dicyano-1,4-benzoquinone) oxidation has been developed. This method offers a convenient high-yield route to xanthones from easily accessible starting materials.
\end{abstract}

iron catalysis, xanthones, oxidation reaction, one-pot process

Citation: $\quad$ Yang J Y, Dong C Y, Li H Y, et al. Iron-catalyzed one-pot reactions of $o$-aryloxybenzaldehydes to xanthones. Chin Sci Bull, 2012, 57: 2364-2367, doi: $10.1007 / \mathrm{s} 11434-012-5144-9$

The xanthone nucleus is the core structure in a large number of natural products and synthetic compounds that exhibit interesting anti-tumor, and anti-inflammatory activities [1-3]. There are a number of known methods for their synthesis [4-13]. The reported procedures generally involve the reaction of a diaryl ether or a benzophenone intermediate [2], and typically require harsh reaction conditions and/or the use of strong acids or expensive metals. Recently, syntheses of xanthones by trapping of arynes with phenol derivatives have been reported [14,15]. The development of sustainable, environmentally benign $\mathrm{C}-\mathrm{C}$ bond-forming processes is very attractive in mordern organic chemistry. Iron-catalyzed reactions have received considerable attention [16-19] because iron catalysts are cheap, non-toxic and easy to synthesize. We are interested in developing new Fe-catalyzed synthetic methods for $\mathrm{C}-\mathrm{C}$ or $\mathrm{C}-\mathrm{X}$ bond formation [20-25]. In this paper, we report the Fe-catalyzed synthesis of xanthones from 2-aryloxybenzaldehydes (eq. (1)).
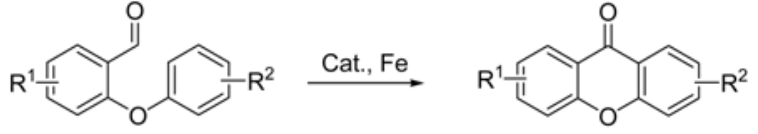

\footnotetext{
*Corresponding author (email: yzli@chem.ecnu.edu.cn)
}

We started our investigation with the reaction of 2-(4methoxyphenoxy) benzaldehyde (1a) in toluene at $120^{\circ} \mathrm{C}$, using $20 \mathrm{~mol} \%$ of $\mathrm{FeCl}_{3}$ as the catalyst. However, after $12 \mathrm{~h}$, only trace amounts of products were detected (Table 1, entry 1). Increasing the amount of $\mathrm{FeCl}_{3}$ to 1.0 equiv resulted in formation of xanthone $\mathbf{2} \mathbf{a}$ and xanthene $\mathbf{3 a}$ in yields of $42 \%$ and $31 \%$, respectively (Table 1 , entry 2). 2.0 equiv of $\mathrm{FeCl}_{3}$ offered similar results as that of 1.0 equiv (Table 1 , entry 3). Other solvents such as DMF, THF, DMSO, NMP resulted in no reaction (Table 1, entries 4-7). $\mathrm{CH}_{3} \mathrm{CN}$ and 1,4-dioxane as solvents also produced $\mathbf{2 a}$ and $\mathbf{3 a}$ in good yields after $12 \mathrm{~h}$ (Table 1, entries 8 and 9). When DCE was used as the solvent, the combined yield of $\mathbf{2 a}$ and $3 \mathbf{a}$ was around $90 \%$ (Table 1, entry 10). Both $\mathbf{2 a}$ and $\mathbf{3 a}$ could be produced by the disproportionation of the corresponding xanthol, and it is possible to convert the xanthol to a xanthone by oxidation. In order to obtain $\mathbf{2 a}$ as the sole product, several oxidants were tested (Table 1, entries 11-15). To our delight, when 1.0 equiv of DDQ was employed, the desired xanthone $\mathbf{2 a}$ was produced in $94 \%$ yield (Table 1, entry 11). Other catalysts such as $\mathrm{CuCl}$ and $\mathrm{Cu}_{2} \mathrm{O}$ failed to accomplish the reaction (Table 1, entries 16 and 17). It was clear that the optimized reaction conditions for xanthone formation were $20 \mathrm{~mol} \% \mathrm{FeCl}_{3}$ as the catalyst with addition 
Table 1 Optimization of reaction conditions for the synthesis of 2a

\begin{tabular}{|c|c|c|c|c|c|c|}
\hline \multirow{2}{*}{ Entry } & \multirow{2}{*}{ Cat. (mol\%) } & \multirow{2}{*}{ Sol. } & \multirow{2}{*}{$T\left({ }^{\circ} \mathrm{C}\right)$} & \multirow{2}{*}{ Time (h) } & \multicolumn{2}{|c|}{ Yield $(\%)^{\text {a) }}$} \\
\hline & & & & & 3a & $2 a$ \\
\hline 1 & $\mathrm{FeCl}_{3}(20)$ & Toluene & 120 & 12 & & Trace \\
\hline 2 & $\mathrm{FeCl}_{3}(100)$ & Toluene & 120 & 12 & 31 & 42 \\
\hline 3 & $\mathrm{FeCl}_{3}(200)$ & Toluene & 120 & 1 & 37 & 44 \\
\hline 4 & $\mathrm{FeCl}_{3}(100)$ & DMF & 135 & 7 & & $\mathrm{NR}^{\mathrm{b})}$ \\
\hline 5 & $\mathrm{FeCl}_{3}(100)$ & THF & 70 & 5 & & $\mathrm{NR}^{\mathrm{b})}$ \\
\hline 6 & $\mathrm{FeCl}_{3}(100)$ & DMSO & 130 & 11 & & $\mathrm{NR}^{\mathrm{b})}$ \\
\hline 7 & $\mathrm{FeCl}_{3}(100)$ & NMP & 130 & 10 & & $\mathrm{NR}^{\mathrm{b})}$ \\
\hline 8 & $\mathrm{FeCl}_{3}(100)$ & $\mathrm{CH}_{3} \mathrm{CN}$ & 80 & 12 & 38 & 38 \\
\hline 9 & $\mathrm{FeCl}_{3}(100)$ & Dioxane & 120 & 12 & 18 & 22 \\
\hline 10 & $\mathrm{FeCl}_{3}(100)$ & DCE & 100 & 5 & 38 & 50 \\
\hline 11 & $\mathrm{FeCl}_{3} \cdot 6 \mathrm{H}_{2} \mathrm{O}(20)$ & DCE & 100 & 62 & - & 94 \\
\hline 12 & $\mathrm{FeCl}_{3} \cdot 6 \mathrm{H}_{2} \mathrm{O}(50)$ & DCE & 100 & 24 & - & 91 \\
\hline 13 & $\mathrm{FeCl}_{3} \cdot 6 \mathrm{H}_{2} \mathrm{O}(20)$ & DCE & 100 & 62 & - & 36 \\
\hline 14 & $\mathrm{FeCl}_{3} \cdot 6 \mathrm{H}_{2} \mathrm{O}(20)$ & DCE & 100 & 62 & - & 10 \\
\hline 15 & - & DCE & 100 & 62 & & Trace \\
\hline 16 & $\mathrm{CuCl}(2)$ & DCE & 100 & 62 & & Trace \\
\hline 17 & $\mathrm{Cu}_{2} \mathrm{O}(5)$ & DCE & 100 & 62 & & Trace \\
\hline
\end{tabular}

a) Isolated yield; b) no reaction.

of 1.0 equiv of DDQ, in DCE at $100^{\circ} \mathrm{C}$.

Having established an effective catalytic system for the xanthone-forming reactions, we next synthesized a variety of $o$-aryloxybenzaldehyde derivatives to explore the scope of the cyclization-oxidation reaction under the optimized conditions. Representative results are shown in Table 2 (spectroscopic date see supporting information). The reaction was applicable to various $o$-aryloxybenzaldehydes. $o$-Aryloxybenzaldehyde $\mathbf{1 b}$ with an electron-donating $(-p-\mathrm{Me})$ aryl group cyclized smoothly to give the xanthone 2b in $94 \%$ yield (Table 2, entry 2). The unsubstituted $o$-aryloxybenzaldehyde $\mathbf{1 c}$ afforded $\mathbf{2 c}$ in $85 \%$ yield (Table 2 , entry 3), and 1d, with an electron-withdrawing $(-p-\mathrm{Cl})$ aryl group, gave $2 \mathbf{f}$ in $71 \%$ yield (Table 2, entry 4). 2,4-Dichloro-substituted 1e afforded 2e in medium yield (Table 2, entry 5). Substituents could also be present on the aromatic ring bearing the formyl group, for example, $1 \mathrm{~g}$ and $\mathbf{1 h}$, and the corresponding xanthones $\mathbf{2 g}$ and $\mathbf{2 h}$ were obtained in high yields under the standard conditions, respectively (Table 2, entries 6,7). When 1i with a 2-naphthyl group was subjected to the optimal reaction conditions, the desired tetracyclic product was produced in $95 \%$ yield (Table 2, entry 9). The substrate scope of the reaction could also be extended to other $o$-substituted benzaldehydes, such as phenylthiobenzaldehyde and biphenyl-2-carbaldehyde. It

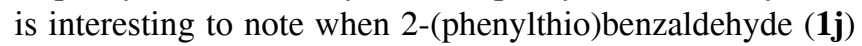
was employed, the corresponding thioxanthone $\mathbf{2} \mathbf{j}$ was obtained in 55\% yield (Table 2, entry 10). Biphenyl-2carbaldehyde (1k) furnished fluorenone (2k) in $70 \%$ yield (Table 2, entry 11). These results may further broaden the substrate scope of these reactions.

Based on the above observations and the reported results $[13,15]$, a plausible reaction mechanism is proposed in Scheme 1. Intramolecular Friedel-Crafts reaction of $\mathbf{1}$ to produce $\mathbf{4}$, proton transfer to form xanthol $\mathbf{5}$, and then oxidation to give the desired xanthone $\mathbf{2}$.

In summary, we have reported an efficient iron-catalyzed cascade cyclization-oxidation process for conversion of 2 -aryloxybenzaldehydes to xanthone derivatives. The reactions proceed to afford xanthone derivatives in good to high yields, using $\mathrm{FeCl}_{3} \cdot 6 \mathrm{H}_{2} \mathrm{O}$ as the catalyst and DDQ as the oxidant in DCE. Further investigations of this novel iron-catalyzed procedure to extend the scope of synthetic applications are in progress.

Typical procedure for the iron-catalyzed formation of xanthone (2a): $\mathrm{FeCl}_{3} \cdot 6 \mathrm{H}_{2} \mathrm{O}$ (54 mg, $20 \mathrm{~mol} \%$ ), 2-(4-methoxyphenoxy)benzaldehyde (1a) (228 mg, $1.0 \mathrm{mmol})$, DDQ (227 mg, $1.0 \mathrm{mmol})$, and DCE $(5 \mathrm{~mL})$ were added to a 
Table 2 Synthesis of xanthones from $o$-aryloxybenzaldehydes

\begin{tabular}{|c|c|c|c|c|}
\hline Entry & Substrate & Time (h) & Product & Yields $(\%)^{\text {a) }}$ \\
\hline 1 & & 62 & & 94 \\
\hline 2 & & 50 & & 94 \\
\hline 3 & & 62 & & 85 \\
\hline 4 & & 80 & & 71 \\
\hline 5 & & 70 & & 40 \\
\hline 6 & & 62 & & 93 \\
\hline 7 & & 36 & & 95 \\
\hline 8 & & 62 & & 86 \\
\hline 9 & & 62 & & 95 \\
\hline 10 & & 64 & & $55^{\mathrm{b})}$ \\
\hline 11 & & 8 & & 70 \\
\hline
\end{tabular}

a) Isolated yield; b) $50 \mathrm{~mol} \%$ of $\mathrm{FeCl}_{3} \cdot 6 \mathrm{H}_{2} \mathrm{O}$ was used.

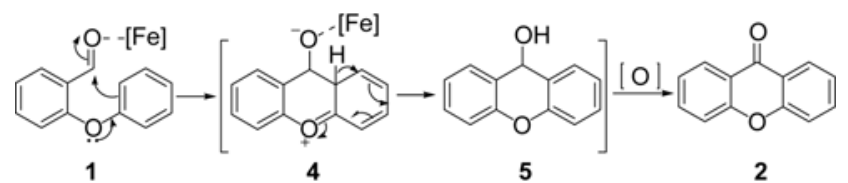

Scheme 1 Proposed reaction mechanism.

Schlenk tube under nitrogen. The resulting solution was stirred at $100^{\circ} \mathrm{C}$ for $62 \mathrm{~h}$. Then the reaction was quenched with distilled water and filtered with celite. The organic layer was separated, and the aqueous layer was extracted with EtOAc. The combined organic layer was washed with brine and dried over $\mathrm{MgSO}_{4}$. The solvent was evaporated under reduced pressure, and the product was isolated by chromatography on a silica-gel column to give $\mathbf{2 a}$ as a white solid in $94 \%$ isolated yield. ${ }^{1} \mathrm{H}$ NMR $\left(400 \mathrm{MHz}, \mathrm{CDCl}_{3}\right.$, $\left.\mathrm{Me}_{4} \mathrm{Si}\right) \delta 3.82(\mathrm{~s}, 3 \mathrm{H}), 7.21-7.38(\mathrm{~m}, 4 \mathrm{H}), 7.59-7.60(\mathrm{~m}, 2 \mathrm{H})$, $8.24(\mathrm{dd}, J=8.6,1.2 \mathrm{~Hz}, 1 \mathrm{H}) ;{ }^{13} \mathrm{C}$ NMR $(100.6 \mathrm{MHz}$, $\left.\mathrm{CDCl}_{3}, \mathrm{Me}_{4} \mathrm{Si}\right) \delta 55.79,105.81,117.91,119.34,121.19$,
$122.05,123.66,124.81,126.63,134.52,150.97,155.98$, $155.11,177.06$

This work was supported by the National Natural Science Foundation of China (20872037).

1 Kenji M, Yukihiro A, Hong Y, et al. Bioorg Med Chem, 2004, 12 : 5799-5806

2 Pedro M, Cerqueira F, Sousa M E, et al. Bioorg Med Chem, 2002, 10: 3725-3730

3 Schwaebe M K, Moran T J, Whitten J P. Tetrahedron Lett, 2005, 46: 827-829

4 Sousa M E, Pinto M M M. Curr Med Chem, 2005, 12: 2447-2479

5 Johnson M M, Naidoo J M, Fernandes M A, et al. J Org Chem, 2010, 75: 8701-8704

6 Giri R, Goodell J R, Xing C, et al. Bioorg Med Chem, 2010, 18: $1456-1463$

7 Wang S Z, Xie K, Tan Z, et al. Chem Commun, 2009, 6469-6471

8 Hintermann L, Masuo R, Suzuki K. Org Lett, 2008, 10: 4859-4862

9 Barbero N, SanMartin R, Dominguez E. Tetrahedron, 2009, 65: $5729-5732$ 
10 Suzuki Y, Toyota T, Miyashita A, et al. Chem Pharm Bull, 2006, 54: 1653-1658

11 Familoni O B, Ionica I, Bower J F, et al. Synlett, 1997, 1081-1083

12 Moreau S, Varache-Lembege M, Larrouture S, et al. Eur J Med Chem, 2002, 37: 237-253

13 Kuo C W, Fang J M. Synth Commun, 2001, 31: 877-892

14 Zhao J, Larock R C. Org Lett, 2005, 7: 4273-4275

15 Okuma K, Nojima A, Matsunaga N, et al. Org Lett, 2009, 11: 169-171

16 Correa A, Mahcheno O G, Bolm C. Chem Soc Rev, 2008, 37: 11081117
17 Norinder J, Matsumoto A, Yoshikai N, et al. J Am Chem Soc, 2008, 130: 5858-5859

18 Liu W, Li Y, Liu K, et al. J Am Chem Soc, 2011, 133: 10756-10759

19 Liu W, Liu J, Ogawa D, et al. Org Lett, 2011, 13: 6272-6275

20 Li H, Xu X, Yang J, et al. Tetrahedron Lett, 2011, 52: 530-533

21 Xu X, Xu X, Li H, et al. Org Lett, 2010, 12: 100-103

22 Xie X, Xu X, Li H, et al. Adv Synth Catal, 2009, 351: 1263-1267

23 Xu X, Liu J, Liang L, et al. Adv Synth Catal, 2009, 351: 2599_ 2604

24 Li H, Yang J, Liu Y, et al. J Org Chem, 2009, 74: 6797-6801

25 Yang J, Wang C, Xie X, et al. Eur J Org Chem, 2010, 4189-4193

Open Access This article is distributed under the terms of the Creative Commons Attribution License which permits any use, distribution, and reproduction in any medium, provided the original author(s) and source are credited.

\section{Supporting Information}

Experimental details and spectroscopic characterization of all new compounds.

The supporting information is available online at csb.scichina.com and www.springerlink.com. The supporting materials are published as submitted, without typesetting or editing. The responsibility for scientific accuracy and content remains entirely with the authors. 